\title{
EFICIÊNCIA DE FUNGOS MICORRÍZICOS ARBUSCULARES SOBRE O CRESCIMENTO DO PORTA-ENXERTO DE PESSEGUEIRO ‘ALDRIGHI’ (1)
}

\author{
JOSÉ LUIS DA SILVA NUNES $\left(\left(^{*}\right)\right.$; PAULO VITOR DUTRA DE SOUZA $(3,5)$; \\ GILMAR ARDUINO BETTIO MARODIN $\left({ }^{3,5}\right)$; JOSÉ CARLOS FACHINELLO $\left({ }^{4,5}\right)$
}

\begin{abstract}
RESUMO
Este trabalho visou avaliar a eficiência de diferentes espécies de fungos micorrízicos arbusculares (FMAs) sobre o crescimento vegetativo e o conteúdo de nutrientes de plantas do porta-enxerto de pessegueiro (Prunus persica) cv. Aldrighi. O experimento foi realizado no município de Eldorado do Sul (RS), entre 2004 e 2005. Foram utilizados quatro tratamentos de inoculação de estirpes de FMAs (Acaulospora sp. Trappe, Glomus clarum Nicol. \& Schenck, Glomus etunicatum Becker \& Gerd e Scutellospora heterogama Nicol. \& Gerd.) e um tratamento testemunha, sem inoculação. O delineamento experimental utilizado foi o de blocos casualizados, com 20 plantas por parcela e quatro repetições. A altura das plantas, o diâmetro do colo, a área foliar, as biomassas fresca e seca, o conteúdo em nutrientes e em substâncias da parte aérea e das raízes e a colonização das raízes foram avaliados aos 180 dias após a semeadura. O uso das espécies de FMAs beneficia o desenvolvimento de plantas do porta-enxerto cv. Aldrighi, e a eficiência da simbiose planta-FMAs é variável com a espécie de FMAs inoculada. As plantas submetidas à inoculação com S. heterogama e G. etunicatum destacaram-se das demais, com maior crescimento vegetativo e maiores teores de nitrogênio, fósforo e potássio nos tecidos.
\end{abstract}

Palavras-chave: Prunus persica, endomicorrizas, nutrição, crescimento.

\section{ABSTRACT \\ EFFICIENCY OF ARBUSCULAR MYCORRHIZAL FUNGI ON GROWTH OF ‘ALDRIGHI' PEACH TREE ROOTSTOCK}

This work aimed to evaluate the eficiency of four species of arbuscular mycorrhizal fungi (AMF) on the vegetative growth and the nutrient contents of peach tree rootstocks (Prunus persica) cv. Aldrighi. The experiment was conducted at the Estação Experimental Agronômica (EEA) of the Universidade Federal do Rio Grande do Sul (UFRGS), Eldorado do Sul, RS, during 2004 and 2005. Four treatments of AMF inoculation strains (Acaulospora sp. Trappe, Glomus clarum Nicol. \& Schenck, Glomus etunicatum Becker \& Gerd e Scutellospora heterogama Nicol. \& Gerd.) and one with non-inoculated plants were used. A randomized block design was used, with 20 plants per plot and four replicates, totaling 80 plants per treatment. Stem height and diameter, leaf area, fresh and dry biomass of the stem and roots, nutrients and carbohidrate contents and root colonization were evaluate at 180 days after sowing. The use of AMF species benefits plant development of rootstock cv. Aldrighi, and the efficiency of AMF-plant symbiosis is variable according to the inoculated AMF species. The rootstocks inoculated with S. heterogama and G. etunicatum performed best presenting larger vegetative growth and higher nitrogen, phosphorus and potassium tissue contents.

Key words: Prunus persica, endomycorrhiza, nutrition, growth development.

$\left({ }^{1}\right)$ Recebido para publicação em 5 de março de 2008 e aceito em 28 de maio de 2009.

$\left({ }^{2}\right)$ Rua Silvio Silveira Soares, 2406/130, 91910-460 Porto Alegre (RS). E-mail: silva.nunes@ufrgs.br $\left(^{*}\right)$ Autor correspondente.

$\left({ }^{3}\right)$ PPG Fitotecnia, Departamento de Horticultura e Silvicultura, Faculdade de Agronomia, Universidade Federal do Rio Grande do Sul, 91501-970 Porto Alegre (RS).E-mail: pvdsouza@ufrgs.br, marodin@ufrgs.br

( $\left.{ }^{4}\right)$ Departamento Fitotecnia, FAEM, Universidade Federal de Pelotas, Caixa Postal 354, 96010-900 Pelotas (RS). E-mail: jfachi@ufpel.tche.br

$\left({ }^{5}\right)$ Bolsista CNPq. 


\section{INTRODUÇÃO}

Um dos entraves à fruticultura refere-se à produção de mudas de qualidade. Esta qualidade é diretamente proporcional à presença de microrganismos benéficos, como os fungos micorrízicos arbusculares (FMAs), que são eliminados naqueles viveiros cujo o solo é desinfestado (SouzA, 2000), ou estão em quantidades insignificantes, no caso de mudas produzidas em recipientes, com substratos excessivamente adubados (SouzA et al., 2005).

Os FMAs, além de melhorarem o estado nutricional das mudas, aceleram seu crescimento e melhoram o vigor na fase de formação (BolletTA et al., 2002). Também favorecem a adaptação das plantas a diferentes ecossistemas, aumentando a tolerância a fatores estressantes bióticos e abióticos (Silveira et al., 2002).

A eficiência da simbiose é representada pela capacidade dos FMAs em estimular o crescimento da planta e depende da genética do fungo e do hospedeiro e dos fatores edafoclimáticos envolvendo os dois agentes (HARrison, 1999). Assim, em uma cultivar pode ocorrer baixa suscetibilidade a um determinado isolado de FMA e ótima resposta quando submetida à inoculação com outro (MOREIRA e SiQUEIRA, 2002).

Nunes et al. (2008) observam que em mudas de porta-enxerto de pessegueiro da cv. Aldrighi submetidas à inoculação com FMAs pode ocorrer maior desenvolvimento vegetativo, sendo a eficiência da simbiose dependente da espécie de FMAs utilizada. CALvet et al. (2003) destacam que, apesar de toda a evidência experimental que aponta para o efeito positivo da simbiose micorrízica no desenvolvimento de porta-enxertos de frutíferas, maiores estudos devem ser realizados, como no caso específico de pessegueiro. Conforme Berta et al. (1995), as condições em que a associação entre os FMAs e as plantas é estabelecida, principalmente com relação ao isolado de FMAs a ser utilizado, parece ser crucial para explorar ao máximo os benefícios desta associação, como resistência ao transplantio, à salinidade, à seca e ao aumento de tolerância a doenças de solo e a fitonematóides.

O objetivo deste trabalho foi avaliar a eficiência de espécies de FMAs sobre o desenvolvimento vegetativo, o conteúdo em nutrientes e em reservas de plantas do porta-enxerto de pessegueiro (Prunus persica) cv. Aldrighi.

\section{MATERIAL E MÉTODOS}

Caroços do porta-enxerto da cv. Aldrighi foram estratificados em recipientes (caixa plástica de $40 \mathrm{~cm} \times 28 \mathrm{~cm} \times 10 \mathrm{~cm}$ ) contendo areia e colocados, por um período de 45 dias, em refrigerador à temperatura de $4{ }^{\circ} \mathrm{C}$, visando interromper a dormência do embrião e facilitar a germinação. A areia foi previamente autoclavada a $120^{\circ} \mathrm{C}$ por uma hora. Essa operação foi realizada no laboratório do Departamento de Horticultura e Silvicultura, da Faculdade de Agronomia da Universidade Federal do Rio Grande do Sul (UFRGS).

Logo após o período de estratificação, as sementes foram retiradas dos caroços e semeadas em caixas plásticas $(40 \mathrm{~cm} \times 28 \mathrm{~cm} \times 10 \mathrm{~cm})$, preenchidas com areia desinfestada e mantidas em casa de vegetação. Quando as plântulas estavam com cerca de $5 \mathrm{~cm}$ de altura da parte aérea foram repicadas e colocadas em sacos plásticos pretos $(5$ litros), contendo substrato constituído de terra oriunda de um solo ARGISSOLO VERMELHO distrófico típico (EMBrapa, 1999), areia (granulometria média, entre 0,6 e $1 \mathrm{~mm}$ ) e resíduo decomposto de casca de acácia negra (1:1:1, v:v.v). O substrato foi previamente desinfestado com solução de formaldeído, a 10\%. Uma amostra do substrato foi coletada visando à determinação do percentual de matéria orgânica e de macronutrientes, além do $\mathrm{pH}$, segundo método de Tedesco et al. (1995) (Tabela 1).

Tabela 1. Potencial hidrogeniônico (pH), matéria orgânica (M.O.) e macronutrientes encontrados no substrato utilizado no cultivo de porta-enxertos da cv. Aldrighi. Dados obtidos na implantação do experimento

\begin{tabular}{cccccc}
\hline $\mathrm{pH}$ & M.O. & $\mathrm{P}$ & $\mathrm{K}$ & $\mathrm{Ca}$ & $\mathrm{Mg}$ \\
\hline & $\%$ & $\mathrm{mg} \mathrm{dm}^{-3}$ & & $\mathrm{cmol}_{\mathrm{c}} \mathrm{L}^{-1}$ & 4,2 \\
\hline, 3 & 3,7 & 8,4 & 48 & 2,1 \\
\hline
\end{tabular}


Imediatamente antes da repicagem procedeuse à adição dos inóculos de FMA ao substrato (30 gramas por saco plástico, 15 esporos por grama de inóculo), em uma camada situada na altura intermediária de cada recipiente (aproximadamente a $15 \mathrm{~cm}$ de altura). O inóculo era constituído de raízes e solo rizósférico de orégano (Origanum vulgare Link), espécie vegetal utilizada para multiplicar, através de cultivo monospórico, cada uma das espécies de FMAs. Os esporos foram isolados a partir de amostras de solo coletadas em vinhedos da serra gaúcha, através do método de lavagem, decantação, peneiramento (GERDERMANN e Nicolson, 1963) e centrifugação (JenKINS, 1964). A identificação morfológica das espécies foi realizada através da observação em microscópio óptico, segundo Schenck \& Perez (1988). As espécies de FMAs testadas foram Acaulospora sp. (Trappe), Glomus clarum (Nicol. \& Schenck) e Glomus etunicatum (Becker \& Gerd) e Scutellospora heterogama (Nicol. \& Gerd), além das testemunhas, que não receberam inóculo. O delineamento experimental utilizado foi o de blocos casualizados, com cinco tratamentos, quatro repetições por tratamento e vinte plantas por repetição.

O experimento foi desenvolvido em casa de vegetação equipada com sistema de irrigação por nebulização, em Eldorado do Sul (RS), tendo início em 21 de setembro de 2004 e término em 21 de março de 2005.

Aos 180 dias após a semeadura foi feita avaliação da altura, desde o colo até o ápice da haste principal, com uso de trena, e do diâmetro da haste principal, na altura do colo das plantas, com uso de paquímetro da marca RS Baty. Além disso, cinco plantas de cada repetição foram usadas para a determinação da área foliar, através do uso de medidor de área foliar marca Li-Cor LI - 3000, e biomassa fresca e seca da parte aérea e raízes, através de pesagem inicial (matéria fresca) e após sua secagem a $65{ }^{\circ} \mathrm{C}$ até massa constante (matéria seca). As amostras secas foram moídas, sendo delas retirada uma fração para avaliação de conteúdo em nutrientes por digestão, destilação e espectrofotometria de chamas do tecido vegetal, conforme método de TEDESCO et al. (1995). Um grama de cada amostra foi acondicionado em tela especial para filtragem de alimentos, anotando-se a massa de cada tela antes e após serem submetidos a processo de digestão em solução aquosa com 5\% de ácido tricloroacético (99\%) e 35\% de metanol (99\%), visando à extração de todos os componentes do tecido vegetal (carboidratos, gorduras, ácidos graxos, etc.), que não fossem fibras (celulose, hemicelulose e lignina), conforme convencionado como substâncias de reserva no método descrito por Priestley (1965).
Segmentos de raízes secundárias foram coletados para determinar a colonização radicular (n. ${ }^{\circ}$ segmentos infectados / total analisado x 100) e índices de presença de hifas (0 - ausência; 1 - fraca; 2 moderada; 3 - intensa), vesículas e arbúsculos (0: ausência; 1: 1a 50; 2: 51 a 100; 3: mais de 100 estruturas/cm de radicela) (NemEc, 1992). Para isto, avaliaram-se 30 frações de radicelas de um centímetro de cada tratamento, que foram lavadas em água destilada, clarificadas por 8 minutos com $\mathrm{KOH}(10 \%)$ e coradas com azul-de-Tripano em lactoglicerol 0,05\% (Phillips e Hayman, 1970).

Os dados foram submetidos à análise de variância executada pelo programa SAS e as médias foram comparadas pelo teste de Duncan ao nível de 5\% de significância (transformação: arco seno vx/100). Foram feitas análises de correlação simples entre parâmetros de crescimento e percentual de macronutrientes das plantas e colonização radicular (definido pelo número de segmentos infectados por estruturas de colonização - hifas, vesículas e arbúsculos / total segmentos analisados) por FMAs, empregando-se o coeficiente de correlação de Pearson (r) com valores máximos representados por $\mathrm{r}=1$ e $\mathrm{r}=-1$.

\section{RESULTADOS E DISCUSSÃO}

Para a variável altura dos porta-enxertos, somente as espécies S. heterogama e G. etunicatum foram eficientes, sendo mais marcante o efeito da primeira espécie (Tabela 2). Nas demais variáveis de crescimento vegetativo avaliadas, todas as espécies de FMAs foram eficazes, apenas variando a intensidade de resposta, excetuando-se a biomassa fresca da parte aérea de plantas tratadas com G. clarum, que foi semelhante ao das plantas testemunhas. Em todas as avaliações, S. heterogama proporcionou maior crescimento do que as demais espécies de FMAs, enquanto G. etunicatum propiciou o desenvolvimento de plantas com altura, diâmetro do colo e biomassa fresca e seca da parte aérea intermediário, sendo inferior a $S$. heterogama e superior aos demais tratamentos. A área foliar e biomassa fresca e seca das raízes foram semelhantes em plantas infectadas com Acaulospora sp., G. clarum e G. etunicatum, com valores superiores aos observados em plantas não inoculadas.

Segundo Locatelli e Lovato (2002), nas simbioses micorrízicas, a especificidade entre fungo e planta não existe. Porém, HaAs e Menge (1990) e SiLva e SiqueIRA (1991) observaram que as espécies de FMAs respondem de forma diferenciada aos fatores climáticos e às características químicas e físicas do solo. 
Tabela 2. Altura de parte aérea, diâmetro do colo, área foliar (AF), biomassa fresca (BF) e biomassa seca (BS) da parte aérea e das raízes das plantas submetidas à inoculação com quatro espécies de FMA e sem inoculação, aos 180 dias após a semeadura

\begin{tabular}{|c|c|c|c|c|c|c|c|}
\hline \multirow{2}{*}{ Tratamento } & \multirow{2}{*}{ Altura } & \multirow{2}{*}{ Diâmetro } & \multirow{2}{*}{$\mathrm{AF}$} & \multicolumn{2}{|c|}{ Parte Aérea } & \multicolumn{2}{|c|}{ Raízes } \\
\hline & & & & $\mathrm{BF}$ & BS & $\mathrm{BF}$ & BS \\
\hline & $\mathrm{cm}$ & $\mathrm{mm}$ & $\mathrm{cm}^{2} /$ planta & 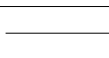 & 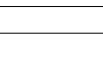 & 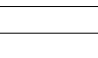 & 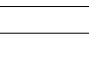 \\
\hline Acaulospora sp. & $130,94 \mathrm{c}$ & $6,28 c$ & $602,89 \mathrm{~b}$ & $125 c$ & $53 c$ & $79 b$ & $26 b$ \\
\hline G. clarum & $129,80 \mathrm{c}$ & $6,24 c$ & $577,27 \mathrm{~b}$ & $114 \mathrm{~cd}$ & $49 c$ & $79 b$ & $26 b$ \\
\hline G. etunicatum & $138,36 b$ & $6,82 b$ & $604,99 \mathrm{~b}$ & $137 b$ & $63 b$ & $70 \mathrm{~b}$ & $26 b$ \\
\hline S. heterogama & $143,97 a$ & $7,29 a$ & $752,22 a$ & $173 a$ & $74 a$ & $113 a$ & $40 a$ \\
\hline Testemunha & $129,70 \mathrm{c}$ & $5,88 \mathrm{~d}$ & $532,06 \mathrm{c}$ & $105 d$ & $42 d$ & $60 c$ & $20 c$ \\
\hline $\mathrm{CV}(\%)$ & 1,55 & 2,77 & 6,12 & 12,44 & 13,22 & 12,25 & 13,40 \\
\hline
\end{tabular}

Médias seguidas pela mesma letra, na coluna, não diferem entre si pelo teste de Duncan ao nível de 5\% de significância.

Além disso, têm sido relatadas diferenças entre as espécies de FMAs na promoção do crescimento e desenvolvimento de uma mesma espécie vegetal, sendo interpretadas como compatibilidade funcional entre o hospedeiro e o fungo (Locatelli e Lovato, 2002; Silveira et al., 2002). Tais relatos corroboram os dados deste estudo visto que, em condições ambientais e substratos semelhantes, os resultados foram diferenciados entre as espécies de FMAs testados.

A área foliar é um importante parâmetro, por definir a taxa de fotossíntese realizada na planta, que resulta na maior ou menor produção de fotoassimilados que serão, em parte, translocados para os FMAs (CAvalCANTE et al., 2002). Silva et al. (2004) afirmam que o aumento da taxa fotossintética de plantas submetidas à inoculação com FMAs está diretamente relacionado ao aumento da área foliar, o que proporciona aumento do crescimento vegetativo e acúmulo de biomassa fresca e seca. $\mathrm{O}$ incremento na área foliar proporcionado pelos FMAs coincide com os resultados observados por CAVALCANTE et al. (2002), em maracujazeiro-amarelo, e Costa et al. (2005), em mangabeira, os quais verificaram que a simbiose planta-FMAs aumentou a área foliar das frutíferas em relação às plantas não infectadas.

Diversos autores (Read e Boyd, 1986; Allen, 1991; SiLveira et al., 2002) relataram que a diferença observada entre a biomassa fresca da parte aérea de plantas inoculadas e não-inoculadas pode ser atribuída à característica dos FMAs em promover maior absorção e conteúdo de água em plantas micorrizadas. SALIENDRA et al. (1995) e Auge (2001) observam que a simbiose micorrízica proporciona alterações nas taxas de absorção de água em plantas hospedeiras, com consequentes efeitos na hidratação dos tecidos, na biomassa fresca e na fisiologia das folhas. Tais relatos corroboram os resultados obtidos neste estudo para Acaulospora sp., G. etunicatum e $S$. heterogama, não coincidindo, porém, para G. clarum.

Silveira et al. (2002) observaram que a biomassa seca pode ter desenvolvimento semelhante entre plantas infectadas e não infectadas. SiqueIRA et al. (1998), por outro lado, afirmaram que a inoculação das plantas pode promover aumentos da biomassa seca, os quais podem variar de $10 \%$ a $800 \%$, sendo as maiores e mais consistentes respostas observadas em plantas jovens, na fase de viveiro. Neste estudo, os resultados relativos à biomassa seca não foram iguais, e em plantas submetidas à inoculação com os FMAs, o desenvolvimento foi superior à testemunha, o que pode ser atribuído à maior área foliar, que contribuiu para o acúmulo de biomassa seca, em resposta à maior produção de fotoassimilados (Minhone e Auler, 2003).

Em plantas infectadas com $S$. heterogama ocorreram os maiores teores em macronutrientes, quando comparadas às demais, excetuando-se cálcio e magnésio, tanto na parte aérea como nas raízes, onde o resultados dos tratamentos com FMAs foi semelhante (raízes) ou inferior (parte aérea) às nãoinoculadas (Tabela 3). Os teores de nitrogênio no tratamento com G. etunicatum, tanto para parte aérea como para raízes, foi superior aos tratamentos com Acaulospora sp. e G. clarum, que foram iguais entre si e maiores às não-inoculadas, para a parte aérea, e iguais para as raízes. Ao propiciar maior absorção de nitrogênio, os FMAs provavelmente contribuíram para que houvessem maiores respostas em termos de crescimento, área foliar e biomassa fresca e seca, às plantas submetidas à inoculação considerando que o nitrogênio é vital para o crescimento vegetativo (Tedesco et al., 1995). Segundo Marschner e Dell (1994), a contribuição das micorrizas para o aumento 
da absorção de nitrogênio pode ser estimada entre $10 \%$ e $15 \%$, podendo chegar a $25 \%$ (Siqueira et al., 2002), em função da capacidade das hifas de crescer além da zona de esgotamento que se forma próximo à superfície das raízes absorventes.

O percentual de fósforo em plantas com $G$. etunicatum foi igual ao das plantas submetidas à inoculação com $S$. heterogama e superior às das tratadas com Acaulospora sp. e G. clarum, que foram iguais ao verificado em plantas não-inoculadas. Nas raízes, os tratamentos com Acaulospora sp., G. clarum e G. etunicatum resultaram em comportamento intermediário para este nutriente, sendo superiores às não-inoculadas, porém inferiores ao tratamento com S. heterogama. Para o potássio, em plantas infectadas com G. etunicatum o conteúdo na parte aérea foi semelhante a $S$. heterogama e superior a todos os outros tratamentos; com G. clarum e Acaulospora sp. o desenvolvimento foi semelhante entre si e superior às não-inoculadas. Nas raízes, o tratamento com G. etunicatum proporcionou percentual de potássio superior às plantas tratadas com Acaulospora sp., que foram superiores às das plantas tratadas com G. clarum e às não inoculadas, e estas tiveram desenvolvimento semelhante entre si (Tabela 3).

Tabela 3. Macronutrientes e substâncias de reserva encontrados na parte aérea (folhas e hastes) e raízes de plantas da cv. Aldrighi submetidas à inoculação com quatro espécies de FMA e sem inoculação, aos 180 dias após a semeadura

\begin{tabular}{|c|c|c|c|c|c|c|}
\hline Tratamento & $\mathrm{N}$ & $\mathrm{P}$ & K & $\mathrm{Ca}$ & $\mathrm{Mg}$ & Substância de reserva \\
\hline & & & & & & \\
\hline \multicolumn{7}{|l|}{ Parte aérea } \\
\hline Acaulospora sp. & $2,99 \mathrm{c}$ & $0,16 b$ & $2,40 \mathrm{~b}$ & $1,34 \mathrm{~d}$ & $0,54 b$ & $34,69 b$ \\
\hline G. clarum & $2,96 \mathrm{c}$ & $0,17 b$ & $2,44 b$ & $1,41 \mathrm{~cd}$ & $0,54 b$ & $35,50 \mathrm{a}$ \\
\hline G. etunicatum & $3,33 b$ & $0,20 \mathrm{a}$ & $2,72 \mathrm{a}$ & $1,48 \mathrm{bc}$ & $0,55 b$ & $36,61 a$ \\
\hline S. heterogama & $3,74 a$ & $0,22 \mathrm{a}$ & $2,76 a$ & $1,56 b$ & $0,55 b$ & $38,25 a$ \\
\hline Testemunha & $2,65 d$ & $0,16 b$ & $2,29 c$ & $1,71 \mathrm{a}$ & $0,60 \mathrm{a}$ & $28,57 \mathrm{c}$ \\
\hline CV (\%) & 6,64 & 10,60 & 3,97 & 5,50 & 2,64 & 2,76 \\
\hline \multicolumn{7}{|l|}{ Raizes } \\
\hline Acaulospora sp. & $1,80 \mathrm{c}$ & $0,21 b$ & $0,42 \mathrm{c}$ & $0,48 b$ & $0,14 \mathrm{~cd}$ & $22,03 c$ \\
\hline G. clarum & $1,79 \mathrm{c}$ & $0,21 b$ & $0,35 d$ & $0,52 b$ & $0,13 d$ & $22,99 b c$ \\
\hline G. etunicatum & $1,89 \mathrm{~b}$ & $0,24 b$ & $0,55 b$ & $0,69 a$ & $0,15 b c$ & $24,92 b$ \\
\hline S. heterogama & $2,01 \mathrm{a}$ & $0,29 a$ & $0,64 a$ & $0,71 \mathrm{a}$ & $0,16 a b$ & $28,27 a$ \\
\hline Testemunha & $1,76 \mathrm{c}$ & $0,16 c$ & $0,34 \mathrm{~d}$ & $0,75 a$ & $0,17 \mathrm{a}$ & $19,80 \mathrm{c}$ \\
\hline CV (\%) & 4,55 & 12,01 & 5,24 & 13,33 & 9,25 & 3,26 \\
\hline
\end{tabular}

Médias seguidas pela mesma letra, na coluna, não diferem entre si pelo teste de Duncan ao nível de 5\% de significância.

Segundo TEDEsco et al. (1995), o fósforo e o potássio são bastante móveis na planta, porém pouco móveis no solo, sendo transportados lentamente até as raízes. CALVET et al. (2003) afirmam que os FMAs proporcionam maior absorção de nutrientes, principalmente fósforo e potássio, como resultado do aumento da superfície e da capacidade de absorção das raízes promovido pelas hifas e pelo micélio externo dos fungos, permitindo maior acessibilidade aos nutrientes. Além disto, os FMAs proporcionam a utilização de formas não-disponíveis às raízes nãocolonizadas, por solubilização e mineralização dos nutrientes na rizosfera (SIQUeIRA et al., 2002). A eficiência das hifas deve-se ao seu pequeno diâmetro e à grande ramificação no solo, aumentando a superfície de absorção das raízes em até $700 \%$
(Minhoni e Auler, 2003). Segundo Marschner e Dell (1994), os FMAs podem proporcionar aumentos estimados em até $80 \%$ na absorção de fósforo e de $60 \%$ para o potássio (SiQUeIRA et al., 2002). Assim, os FMAs são de vital importância para as plantas, em função de sua capacidade de induzir maior absorção de nutrientes de baixa difusão no solo, o que corrobora os resultados verificados, principalmente para os tratamentos com S. heterogama e G. etunicatum.

Os percentuais de nitrogênio da parte aérea de plantas submetidas à inoculação com S. heterogama e G. etunicatum foram os únicos que se mantiveram dentro da faixa de normalidade para a cultura do pessegueiro (entre $3,26 \%$ e $4,53 \%$ de nitrogênio na planta) (Medeiros e Raseira, 1998; Comissão de QuimicA..., 2004). Nos demais tratamentos, os níveis 
estiveram abaixo da normalidade. Por outro lado, todos os tratamentos estavam dentro da faixa de normalidade para a cultura no que se refere aos percentuais de fósforo (entre $0,15 \%$ e $0,28 \%$ ) e potássio $(1,31 \%$ e $2,06 \%)$ (Medeiros e Raseira, 1998; Comissão de Química..., 2004).

No caso do cálcio da parte aérea, as plantas não-inoculadas revelaram os maiores percentuais de cálcio, enquanto os percentuais deste elemento presentes nos tratamentos com S. heterogama e G. etunicatum foram estatisticamente semelhantes entre si, o mesmo ocorrendo com os tratamentos G. etunicatum e G. clarum. Porém, S. heterogama foi superior a $G$. clarum. Todos foram superiores ao tratamento com Acaulospora sp. Nas raízes, os tratamentos com $S$. heterogama e G. etunicatum tiveram percentuais de cálcio iguais aos das plantas não-inoculadas. Nos tratamentos com G. clarum e Acaulospora sp. os percentuais foram semelhantes entre si e inferiores aos outros tratamentos (Tabela 3). O teor de magnésio presente na parte aérea foi semelhante entre plantas infectadas com estipes de FMAs, porém inferiores ao daquelas não infectadas. Nas raízes, plantas submetidas à inoculação com $S$. heterogama tiveram percentual de magnésio estatisticamente semelhante à testemunha e também àquelas inoculadas com $G$. etunicatum. Por outro lado, em plantas infectadas com G. etunicatum os teores de magnésio foram semelhantes àquelas infectadas com Acaulospora sp., e em todos os tratamentos, os teores de magnésio foram superiores às tratadas com G. clarum (Tabela 3 ).

Segundo Silveira et al. (2002), a diminuição da concentração de cálcio e magnésio em plantas infectadas pode ser devido à sua diluição nos tecidos, em função do incremento no crescimento vegetativo de plantas colonizadas, ou à capacidade dos FMAs em reduzir a absorção desses elementos (SouzA, 2000; SouzA et al., 2005).

Diversos autores observaram a diminuição da concentração de cálcio nos tecidos das plantas de frutíferas quando da inoculação de FMAs, como Agostini (2002), que relatou diminuição na concentração de cálcio em plantas do porta-enxerto de videira 101-14, e CARNIEL (2004) que observou concentração de cálcio abaixo do normal em plantas do porta-enxerto de videira P1103. Esses autores, porém, não observaram diferenças em relação ao magnésio. Nenhum dos autores especifica se a diminuição da concentração deve-se à capacidade dos FMAs de reduzir a absorção de cálcio ou simplesmente por diluição nos tecidos, devido ao aumento do crescimento vegetativo e da biomassa fresca e seca. Por outro lado, Silveira et al. (2002) relatam que plantas de porta-enxerto de abacateiro infectadas com FMAs tiveram níveis mais baixos de cálcio e magnésio nos tecidos das plantas em relação àquelas não-inoculadas, o que foi atribuído pelos autores à capacidade de inibição na absorção destes elementos promovida pelos FMAs. De forma semelhante, SouzA (2000) relata que a inoculação de FMAs em plantas de Citrange Carrizo reduziu a absorção de cálcio e magnésio pelos vegetais. Tais relatos estão em consonância com os resultados verificados com as espécies de FMAs testadas neste trabalho.

Avaliando-se os dados referentes aos percentuais de substâncias de reserva presentes nos tecidos da parte aérea das plantas da cv. Aldrighi verifica-se que as plantas submetidas à inoculação com as espécies de FMAs tiveram percentuais superiores às plantas não-inoculadas (Tabela 3 ). Plantas infectadas com G. clarum, G. etunicatum e S. heterogama foram estatisticamente semelhantes ente si e superiores às infectadas com Acaulospora sp e esta, às não-inoculadas. Nas raízes, em plantas infectadas com S. heterogama observaram-se os maiores valores de substâncias de reserva. Plantas submetidas à inoculação com G. clarum foram estatisticamente semelhantes às infectadas com G. etunicatum, ao mesmo tempo em que foram iguais às infectadas com Acaulospora sp. e às plantas não-inoculadas.

Vários autores relatam que a inoculação de espécies de FMAs favorece o aumento da área foliar de plantas e, por consequência, maior produção de fotoassimilados e acúmulo de biomassa (WRIGHT et al., 1998; Theodoro et al., 2003; Sena et al., 2004; SouzA et al., 2005). Além disso, ao induzir maior diâmetro do caule, os FMAs proporcionam às plantas a capacidade de translocar maior volume de nutrientes e água para a parte aérea, que seriam utilizados no crescimento vegetativo, no acúmulo de biomassa, nos processos metabólicos e fotossintéticos da planta (Mazzoni-Viveiros e Trufem, 2004). Por outro lado, também há um fluxo mais intenso de carboidratos no sentido radicular, onde parte seria utilizada pelos FMAs na sua nutrição e parte acumulada nos tecidos de armazenamento da planta, na forma de substâncias de reserva (SCATtENA e SCREMIN-Dias, 2003). Tais relatos ratificam os dados obtidos neste trabalho, com relação às substâncias de reserva da parte aérea, pois todas as espécies de FMAs utilizadas proporcionaram aumento da área foliar em relação às espécies nãoinoculadas.

Altos percentuais de colonização das raízes (acima de 90\% de segmentos de raiz colonizados) somente ocorreram com os tratamentos de inoculação com as espécies S. heterogama e G. etunicatum (Tabela 4), enquanto com G. clarum e Acaulospora sp. a 
colonização foi baixa (em torno de $30 \%$ ). Para as estruturas de colonização, os índices foram considerados medianos para S. heterogama e G. etunicatum e baixos para os outros tratamentos com FMAs (NeMEC, 1992). S. heterogama proporcionou os maiores índices de hifas e arbúsculos nas plantas, seguido de G. etunicatum, com Acaulospora sp. e G. clarum não havia diferenças significativas (Tabela 4). Quanto às vesículas, G. etunicatum proporcionou os maiores valores, enquanto Acaulospora sp. e G. clarum tiveram valores semelhantes (Tabela 4). As raízes das plantas não inoculadas não apresentavam estruturas de colonização. A espécie S. heterogama produziu o maior número de esporos no substrato, seguida de $G$. etunicatum, Acaulospora sp. e G. clarum. Na amostra retirada das plantas não-inoculadas não foram observados esporos de FMAs. Cabe salientar que, com relação às vesículas, os fungos do gênero Scutellospora não formam vesículas intrarradiculares, mas sim, células auxiliares extra-radiculares (SILVEIRA et al., 2002).

Tabela 4. Colonização radicular, número médio de esporos/100 gramas de substrato seco e presença de hifas, vesículas e arbúsculos em raízes de plantas da cv. Aldrighi submetidas à inoculação com quatro espécies de FMA e sem inoculação, aos 180 dias após a semeadura

\begin{tabular}{|c|c|c|c|c|c|}
\hline \multirow{2}{*}{ Tratamentos } & \multirow{2}{*}{ Colonização } & \multirow{2}{*}{ Esporos } & \multicolumn{3}{|c|}{ Presença de estruturas de FMA } \\
\hline & & & Hifas & Vesículas & Arbúsculos \\
\hline & $\%$ & & & & \\
\hline Acaulospora sp. & $30,00 c$ & $152 c$ & $0,45 c$ & $0,24 b$ & $0,40 c$ \\
\hline G. clarum & $28,50 \mathrm{c}$ & $133 d$ & $0,44 \mathrm{c}$ & $0,22 b$ & $0,37 \mathrm{c}$ \\
\hline G. etunicatum & $91,50 \mathrm{~b}$ & $189 \mathrm{~b}$ & $1,37 b$ & $0,99 a$ & $1,21 b$ \\
\hline S. heterogama & $97,75 a$ & $205 a$ & $1,60 \mathrm{a}$ & $0,00 \mathrm{c}$ & $1,58 \mathrm{a}$ \\
\hline Testemunha & $0,00 \mathrm{~d}$ & $0 \mathrm{e}$ & $0,00 \mathrm{~d}$ & $0,00 \mathrm{c}$ & $0,00 \mathrm{~d}$ \\
\hline CV $(\%)$ & 2,91 & 10,35 & 11,30 & 6,35 & 8,42 \\
\hline
\end{tabular}

Médias seguidas pela mesma letra, na coluna, não diferem entre si pelo teste de Duncan ao nível de 5\% de significância.

De acordo com Costa et al. (2001), a eficiência da associação entre FMAs e plantas frutíferas, traduzido em respostas de crescimento das plantas, é regulado pelos genótipos envolvidos, em interação com o ambiente (Silveira et al., 2002). Diversos autores afirmam que, além das respostas diferenciadas aos fatores climáticos e de solo, a compatibilidade entre os genótipos dos FMAs e das plantas é determinante para o início do processo de infecção e colonização das raízes (Hass e MENGE, 1990; Silva e Siqueira, 1991; Locatelli e Lovato, 2002; Siqueira et al., 2002; Silveira et al., 2002). Graham e Eissenstat (1994) citam que os mecanismos que desencadeiam o processo de colonização e otimização dos parâmetros de crescimento das plantas envolvem diferentes processos fisiológicos e genéticos, que representam significativo custo de carbono da planta por parte da espécie de FMA e que podem ser regulados pelo genótipo hospedeiro. Desta forma, as observações feitas por estes autores corroboram os dados obtidos neste trabalho.

Foram observadas correlações entre os parâmetros de crescimento e alguns indicadores nutricionais da cv. Aldrighi e a colonização radicular (hifas, vesículas e arbúsculos) pelos FMAs, ou seja, muitas variáveis avaliadas estão associadas, positiva ou negativamente, com o percentual de colonização radicular, independentemente da espécie de FMA infectada (Tabela 5). As correlações foram consideradas altamente significativas $(p<0,01)$ entre a colonização radicular e a altura da planta, o diâmetro do caule, a área foliar, a biomassa fresca da parte aérea e das raízes, a biomassa seca da parte aérea e das raízes, o teor de nitrogênio da parte aérea, o fósforo da parte aérea e das raízes, o potássio da parte aérea e das raízes e as substâncias de reserva da parte aérea e das raízes. Foi considerada significativa $(p<0,05)$ a correlação entre a colonização radicular e o percentual de nitrogênio das raízes. Não se observou correlação com o percentual de colonização das raízes com o percentual de cálcio e magnésio, tanto na parte aérea quanto nas raízes.

Silveira et al. (2002) observaram que correlações positivas indicam uma relação direta entre as variáveis estudadas, significando que, no caso deste estudo, valores elevados de colonização radicular foram responsáveis por valores elevados do parâmetro avaliado. Ao contrário, correlações negativas indicam relações inversas entre as variáveis avaliadas. 
Tabela 5. Correlação entre parâmetros de crescimento e percentual de macronutrientes de plantas e percentual de colonização radicular (número de segmentos infectados por estruturas de colonização - hifas, vesículas e arbúsculos / total segmentos analisados) por FMA, aos 180 dias após a semeadura

\begin{tabular}{|c|c|c|}
\hline Parâmetro & $\mathrm{r}$ & Probabilidade \\
\hline \% Colonização x altura & $0,70^{* *}$ & 0,0006 \\
\hline \% Colonização x diâmetro & $0,93^{* *}$ & 0,0001 \\
\hline \% Colonização x área foliar & $0,76^{* *}$ & 0,0001 \\
\hline \% Colonização x massa fresca da parte aérea & $0,84^{* *}$ & 0,0001 \\
\hline \% Colonização x massa fresca das raízes & $0,60^{* *}$ & 0,0051 \\
\hline \% Colonização x massa seca da parte aérea & $0,84^{* *}$ & 0,0001 \\
\hline \% Colonização x massa seca das raízes & $0,64^{* *}$ & 0,0023 \\
\hline \% Colonização x \% nitrogênio da parte aérea & $0,86^{* *}$ & 0,0001 \\
\hline \% Colonização x \% nitrogênio das raízes & $0,53^{*}$ & 0,0170 \\
\hline \% Colonização x \% fósforo da parte aérea & $0,66^{* *}$ & 0,0016 \\
\hline \% Colonização x \% fósforo das raízes & $0,69^{* *}$ & 0,0007 \\
\hline \% Colonização x \% potássio da parte aérea & $0,89^{* *}$ & 0,0001 \\
\hline \% Colonização x \% potássio das raízes & $0,92^{* *}$ & 0,0001 \\
\hline \% Colonização x \% Cálcio da parte aérea & $-0,12^{\text {ns }}$ & 0,6166 \\
\hline \% Colonização x \% Cálcio das raízes & $0,18^{\mathrm{ns}}$ & 0,4372 \\
\hline \% Colonização x \% Magnésio da parte aérea & $-0,32^{\mathrm{ns}}$ & 0,1746 \\
\hline \% Colonização x \% Magnésio das raízes & $-0,01^{\mathrm{ns}}$ & 0,9505 \\
\hline \% Colonização x \% substâncias de reserva - parte aérea & $0,76^{* *}$ & 0,0001 \\
\hline \% Colonização x \% substâncias de reserva - raízes & $0,63^{* *}$ & 0,0021 \\
\hline
\end{tabular}

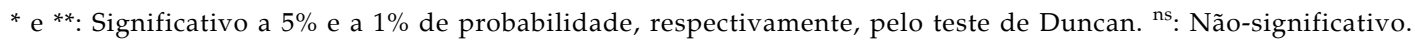

Diversos autores relatam ter observado correlações significativas entre a percentagem de colonização, as respostas de crescimento das plantas e o conteúdo de nutrientes. CHu (1999) e Anjos et al. (2005), que trabalharam com plantas de açaizeiro e maracujazeiro-doce respectivamente, observaram correlações significativas entre os dados de colonização de raízes e crescimento das mudas o que, segundo eles, indicaria que altos percentuais de colonização proporcionaram crescimento elevado. Oliveira et al. (2003), trabalhando com plantas de bananeiras infectadas com FMAs, relatam ter observado correlações positivas significativas entre a percentagem de colonização e os teores de potássio e correlações negativas para cálcio, o que permitiu aos autores inferir que a associação micorrízica foi importante para o estímulo de absorção de potássio e para a diminuição da absorção de cálcio. Oliveira e Oliveira (2004), trabalhando com cupuaçuzeiro e guaranazeiro, constataram correlações significativas positivas entre os percentuais de colonização radicular e os teores de nitrogênio, fósforo e potássio dos tecidos foliares destas plantas, revelando que a colonização por FMAs das raízes está relacionada a elevados teores de macronutrientes foliares. Os resultados destes autores coincidem com os dados obtidos neste estudo.

Costa et al. (2001), trabalhando com plantas de aceroleiras, observaram correlações significativas entre área foliar e biomassa seca para cv. Miró, e altura e biomassa seca para cv. Barbados, não verificando, porém, correlação entre esses parâmetros e o percentual de colonização das raízes, ao contrário do que foi constatado neste trabalho.

\section{CONCLUSÕES}

1. A eficiência da simbiose planta-FMAs é variável com a espécie de FMA infectada.

2. O uso das espécies de FMAs beneficia o desenvolvimento de plantas do porta-enxerto cv. Aldrighi, principalmente quando a inoculação é feita com S. heterogama.

\section{REFERÊNCIAS}

AGOSTINI, S. Influência de fungos micorrízicos arbusculares sobre o desenvolvimento vegetativo de porta-enxertos de 
videira. 2002. 63f. Dissertação (Mestrado em Fitotecnia) Faculdade de Agronomia, Universidade Federal do Rio Grande do Sul, Porto Alegre.

ALLEN, M.F. The ecology of mycorrhizae. San Diego: Cambridge University Press, 1991. 184 p.

ANJOS, E.C.T.; CAVALGANTE, U.M.T.;SANTOS, U.F.; MAIA, L.C. Produção de mudas de maracujá-doce micorrizadas em solo desinfestado e adubado com fósforo. Pesquisa Agropecuária Brasileira, v.40, p.345-351, 2005.

AUGÉ, R.M. Water relations, drought and vesicular-arbuscular mycorrhizal symbiosis. Mycorrhiza, v.11, p.3-42, 2001.

BERTA, G.; TROTTA, A.; FUSCONI, A.; HOOKER, J.E.; MUNRO, M.; ATKINSON, P.; GIOVANNETTI, M.; MORINI, S.; FORTUNA, P. TISSERANTI, B.; GIANINAZZI-PEARSON, V.; GIANINAZZI, S. Arbuscular mycorrhizal induced changes to plant growth and root system morphology in Prunus cerasifera. Tree Physiology, v.15, p.281-293, 1995.

BOLLETTA, A.; RODRÍGUEZ, C.; KRÜGER, H. Interacciones entre hongos micorrízicos e estrés hídrico: su efecto sobre el rendimiento de trigo. Buenos Aires: INTA - EEA Bordenave, 2002. p.1-7. (INTA - Bordenave, 44).

CALVET, C.; ESTAÚN, V.; CAMPRIBÍ, A.; HERNÁNDEZDORREGO, A.; PINOCHET, J.; MORENO, M. A. Aptitude for mycorrhizal root colonization in Prunus rootstocks. Scientia Horticulturae, v. 09, p.1-10, 2003.

CARNIEL, E. Uso de fungos micorrízicos arbusculares no desenvolvimento de porta-enxertos de videira e no controle biológico de Fusarium oxysporum f. sp. herbemontis. 2004. 73 f. Dissertação (Mestrado em Fitotecnia) - Faculdade de Agronomia, Universidade Federal do Rio Grande do Sul, Porto Alegre.

CAVALCANTE, U.M.T.; MAIA, L.C.; MELO, A.M.M.; SANTOS, V.F. Influência da densidade de fungos micorrízicos arbusculares na produção de mudas de maracujazeiro-amarelo. Pesquisa Agropecuária Brasileira, v.37, p.634-649, 2002.

CHU, E. Y. The effects of arbuscular mycorrhizal fungi inoculation on Euterpe oleracea Mart. seedlings. Pesquisa Agropecuária Brasileira, v.34, p.1019-1024, 1999.

COMISSÃO DE QUÍMICA E FERTILIDADE DO SOLO, RS e SC. Manual de adubação e calagem para o Rio Grande do Sul e Santa Catarina. Porto Alegre: SBCS, 2004. 394 p.

COSTA, C.M.C.; MAIA, L.C.; CAVALCANTE, U.M.T.; NOGUEIRA, R.J.M.C. Influência de fungos micorrízicos arbusculares sobre o crescimento de dois genótipos de aceroleira (Malpighia emarginata D.C.). Pesquisa Agropecuária Brasileira, v.36, p.893-901, 2001.

COSTA, C.M.C.; CAVALCANTE,U.M.T.;GOTO, B.T.;SANTOS, V.F.; MAIA, L.C. Fungos micorrízicos arbusculares e adubação fosfatada em mudas de mangabeira. Pesquisa Agropecuária Brasileira, v.40, p.225-232, 2005.
EMPRESA BRASILEIRA DE PESQUISA AGROPECUÁRIA. Centro Nacional de Pesquisa de Solos. Sistema brasileiro de classificação de solos. Brasília, DF, 1999. 412 p.

GEDERMANN, J. W.; NICOLSON, T. H. Spores of mycorrhizal Endogone extracted from soil by wet sieving and decantinf. Transactions of the British Mycological Society, v.46, p.235244, 1963.

GRAHAM, J. H.; EISSENSTAT, D. M. Host genotype and the formation and function of VA mycorrhizae. Plant and Soil, v.159, p 179-185, 1994.

HAAS, J.H.; MENGE, J.A. V.A mycorrhizal fungi and soil characteristics in avocado (Persea americana Mill.) orchard soil. Plant and Soil, v.127, p.207-212, 1990.

HARRISON, M.J. Molecular and cellular aspects of the arbuscular mycorrhizal symbiosis. Annual Review Plant Physiology and Plant Molecular Biology, v.50, p.361$389,1999$.

JENKINS, W. R. A rapid centrifugal-flotation technique for separating nematodes from soil. Plant Diseases Report, v.48, p.691-692, 1964.

LOCATELLI, L.M.; LOVATO, P.E. Inoculação micorrízica e aclimatização de dois porta-enxertos de macieira micropropagados. Pesquisa Agropecuária Brasileira, v.37, p.177-184, 2002.

MARSCHNER, H.; DELL, B. Nutrient uptake in mycorrhizal symbiosis. In: ROBSON, A.D.; ABBOT, L.K.; MALAJCZUK, N. (Ed.). Management of mycorrhizas in agriculture, horticulture and forestry. Dordrecht: Kluwer Academic Publishers, 1994. p.89-102.

MAZZONI-VIVEIROS, S.C.; TRUFEM, S.F.B. Efeitos da poluição aérea e edáfica no sistema radicular de Tibouchina pulchra Cogn. (Melastomataceae) em área de mata Atlântica: associações micorrízicas e morfologia. Revista Brasileira de Botânica, v.27, p.337-348, 2004.

MEDEIROS, C.A.B.; RASEIRA, M. do C. B. A cultura do pessegueiro. Brasília: Embrapa - SPI, 1998. 350 p.

MINHONI, M.T.A.; AULER, P.A.M. Efeito do fósforo, fumigação do substrato e fungo micorrízico arbuscular sobre o crescimento de plantas de mamoeiro. Revista Brasileira de Ciência do Solo, v.27, p.841-847, 2003.

MOREIRA, F.M.S.; SIQUEIRA, J.O. Microbiologia e bioquímica do solo. Lavras: Editora UFLA, 2002. 625 p.

NEMEC, S. Glomus intraradix effects on citrus roostock seedling growth in various potting media. Journal of Agricultural Science, v.118, p.315-323, 1992.

NUNES, J.L.S.; SOUZA, P.V.D.; MARODIN, G.A.D.; FACHINELLO, J.C. Incremento no desenvolvimento do portaenxerto de pessegueiro 'Aldrighi' por fungos micorrízicos arbusculares autóctones. Ciência e Agrotecnologia, v.32, p.1787-1793, 2008. 
OLIVEIRA, A.N.; OLIVEIRA, L.A.; FIGUEIREDO, A.F. Colonização micorrízica e concentração de nutrientes em três cultivares de bananeiras em um Latossolo Amarelo da Amazônia Central. Acta Amazonica, v.33, p.345-352, 2003.

OLIVEIRA, A.N.; OLIVEIRA, L.A. Associação micorrízica e teores de nutrientes nas folhas de cupuazeiro (Theobroma grandiflorum) e guaranazeiro (Paullinia cupuna) de um sistema agroflorestal em Manaus, Amazonas. Revista Brasileira de Ciência do Solo, v.28, p.1063-1068, 2004.

PHILLIPS, J.M.; HAYMAN, D.S. Improved procedures for clearing roots and staining parasitic and vesicular arbuscular mycorrhizal fungi for rapid assessment of infections. Transactions of the British Mycological Society, v.55, p.158161, 1970.

PRIESTLEY, G.A. New method for the estimation of the resources of apple tress. Journal of the Science of Food and Agriculture, v.16, p.717-721, 1965.

READ, D.J.; BOYD, R. Water relations of mycorrhizal fungi and their host plants. In: AYRES, P.G.; BOYD, L. (Ed.). Water, fungi and plants. London: Syndicate of the University of Cambridge, 1986. p.287-303.

SALIENDRA N.Z.; SPERRY J.S.; COMSTOCK J.P. Influence of leaf water status on stomatal response to humidity, hydraulic conductance, and soil drought in Betula occidentalis. Planta, v.196, p.357-366, 1995

SCATENA, V.L.; SCREMIN-DIAS, E. Parênquima, Colênquima e Esclerênquima. In: APPEZZATO-DAGLÓRIA, B.; CARMELLO-GUERREIRO, S. M. (Eds.). Anatomia vegetal. Viçosa: UFV, 2003. p.109-127.

SENA, J.O.A; LABATE, C.A.; CARDOSO, E.J.B.N. Caracterização fisiológica da redução de mudas de citros micorrizadas em altas doses de fósforo. Revista Brasileira da Ciência do Solo, v.28, p.827-832, 2004.

SILVA, M.A.; CAVALCANTE, U.M.T.; SILVA, F.S.B.; SOARES, S.A.G.; MAIA, L.C. Crescimento de mudas de maracujazeirodoce (Passiflora alata Curtis) associadas a fungos micorrízicos arbusculares (Glomeromycota). Acta Botanica Brasilica, v.18, p.981-985, 2004.

SILVA, L.F.C.; SIQUEIRA, J.O. Crescimento e teores de nutrientes de mudas de abacateiro, mangueira e mamoeiro sob influência de diferentes espécies de fungos micorrízicos vesículo arbusculares. Revista Brasileira de Ciência do Solo, v.15, p.283-288, 1991.

SILVEIRA, S.V.; SOUZA, P.V.D.; KOLLER, O. C. Influência de fungos micorrízicos arbusculares sobre o desenvolvimento vegetativo de porta-enxertos de abacateiro. Pesquisa Agropecuária Brasileira, v.37, p.303-309, 2002.

SIQUEIRA, J.O.; SAGGIN-JÚNIOR, O.J.; FLORES-AYLAS, W.W.; GUIMARÃES, P.T.G. Arbuscular mycorrhizal inoculation and superphosphate application influence plant development and yield of cofee in Brazil. Mycorrhiza, v.7, p.293-300, 1998.
SOUZA, P.V.D. Interação entre micorrizas arbusculares e ácido giberélico no desenvolvimento vegetativo de plantas de Citrange Carrizo. Ciência Rural, v.30, p.783-787, 2000.

SOUZA, P.V.D.; CARNIEL, E.; SCHIMITZ, J.A.K.; SILVEIRA, S.V. Influência de substratos e fungos micorrízicos arbusculares no desenvolvimento do porta-enxerto Flying Dragon (Poncirus trifoliata, var. monstruosa Swing.). Revista Brasileira de Fruticultura, v.27, p.285-287, 2005.

TEDESCO, M.J.; GIANELLO, C.; BISSANI, C.A.; BOHNEN, H.; VOLKWEISS, S.J. Análises de solo, plantas e outros materiais. 2.ed. Porto Alegre: UFRGS/ Departamento de solos, 1995. 174p. (Boletim Técnico, 5)

THEODORO, V.C.A.; ALVARENGA, M.I.N.; GUIMARÃES, J.; MOURÃO JUNIOR, M. Carbono da biomassa microbiana e micorriza em solo sob mata nativa e agroecossistemas cafeeiros. Acta Scientiarum: Agronomy, v.25, p.147-153, 2003.

WRIGHT, D.P.; SCHOLES, J.D.; READ, D.J. Effects of VA mycorrhizal colonization on photosynthesis and biomass production of Trifolium repens L. Plant Cell and Environment, v.21, p.209-216, 1998. 